\title{
O ESPANHOL DE VALENÇA NA CLASSE DE E / LE. CONTEXTO TEÓRICO E METODOLOGIA
}

\author{
EL ESPAÑOL DE VALENCIA EN CLASE DE E/LE. CONTEXTO TEÓRICO Y \\ METODOLOGÍA
}

\author{
THE SPANISH OF VALENCIA IN E/LE CLASS. THEORETICAL CONTEXT \\ AND METHODOLOGY
}

David GIMÉNEZ FOLQUÉS ${ }^{1}$

RESUMO: Na Comunidade Valenciana podemos observar uma variedade de espanhol com características próprias, entre outros fatores, devido ao contato lingüístico que ocorre entre o valenciano e o espanhol. Os alunos de E/LE que realizam sua aprendizagem neste contexto geográfico observam em seu ambiente características lingüísticas que não haviam percebido anteriormente e que, na maioria dos casos, desejam incorporar ao seu idioma. Desta forma, o presente trabalho mostra a inclusão do conceito de variedade espanhola na classe E/LE em estudantes americanos que estudaram em Valência. Esse processo foi realizado por meio de atividades que são introduzidas no programa E/LE dos alunos. Por fim, para observar o tom significativo dessa experiência, foram realizados inquéritos com o objetivo de verificar o grau de aquisição das características dessa variedade.

PALAVRAS-CHAVE: Variedades de espanhol. O espanhol de Valência. Espanhol como língua estrangeira. Política linguística.

RESUMEN: En la Comunidad Valenciana podemos observar una variedad del español con características propias, entre otros factores debido al contacto lingüístico que se produce entre el valenciano y el español. Los estudiantes de E/LE que realizan su aprendizaje en este contexto geográfico observan en su entorno características lingüísticas que no habían percibido anteriormente y que, en la mayoría de casos, quieren incorporar a su español. De este modo, en el presente trabajo se muestra la inclusión del concepto de variedad del español en clase de E/LE en alumnos estadounidenses que estudiaron en Valencia. Este proceso se ha llevado a cabo mediante actividades que se introducen en el programa E/LE de los estudiantes. Finalmente, para observar el tono significativo de esta experiencia se llevaron a cabo encuestas con el objetivo de ver el grado de adquisición de las características propias de esta variedad.

\footnotetext{
${ }^{1}$ Universitat de València (UV), Valencia - España. Profesor en el Departamento de Filología Española. ORCID: https://orcid.org/0000-0002-9059-5591. E-mail: david.gimenez-folques@uv.es. Este trabajo se enmarca en el proyecto La atenuación pragmática en su variación genérica: géneros discursivos escritos y orales en el español de España y América (FFI2016-75249-P), financiado por el Ministerio de Economía y Competitividad.
} 
PALABRAS CLAVE: Variedades del español. El español de Valencia. Español como Lengua Extranjera. Política lingüística.

ABSTRACT: In the Community of Valencia we can observe a variety of Spanish with its own characteristics. The students of E/LE that study in this context observe linguistic characteristics that they had not previously perceived and that, in most cases, they want to incorporate into their Spanish. In this way, in the present work the inclusion of the concept of Spanish variety in E/LE class in American students who studied in Valencia is shown. This process has been carried out through activities that are introduced in the E/LE class. Finally, surveys were used with the aim of seeing the acquisition of the characteristics of this variety.

KEYWORDS: Varieties of Spanish. The Spanish of Valencia. Spanish as a Foreign Language. Language policy.

\section{Introducción}

Una de las cuestiones que más se han debatido en los últimos años en las clases de Español como Lengua Extranjera tiene que ver con la elección de la variedad más apropiada para el proceso de enseñanza-aprendizaje. Esta polémica es consecuencia de la riqueza dialectológica que existe actualmente en el idioma, por un lado, y la proyección que está tomando el español en el mundo, por el otro. Debido al creciente interés en la lengua española, hay que considerar el factor de movilidad, ya que son muchos los profesores de español que se trasladan para cubrir la notoria demanda de sus servicios. Según Moreno Fernández (1995), esta demanda de profesores es debida a que el español aparece en el programa educativo de muchos países, a su instrumentalización como lengua extranjera y a la promoción que dedican organismos como el Instituto Cervantes.

Volviendo a la cuestión de la elección de la variedad, encontramos cierto consenso en que cuando la enseñanza se produzca en un país donde el español es lengua nativa, lo lógico es enseñar con la variedad del contexto geográfico, ya que es posible que los estudiantes se hayan movilizado para aprender las características lingüísticas de la zona. En segundo lugar, si el aprendizaje se da en una zona no hispanohablante, la variedad enseñada será la propia del docente. Sin embargo, como se indica en Giménez (2015), conviene concienciar a nuestros alumnos sobre la heterogeneidad de la lengua española y su posible variación dialectal cuando visiten otra zona hispanohablante, aunque llevemos a cabo la enseñanza en una única variedad. De este modo, ayudaremos 
a nuestros estudiantes a evitar el mayor número de conflictos lingüísticos posibles en el ámbito de la movilidad panhispánica, o como mínimo a estar preparados para recibirlos.

En el presente trabajo vamos a analizar una situación de enseñanza concreta con una de estas variedades del español en su contexto geográfico, es decir, el español de Valencia. En esta zona encontramos características propias de una zona de contacto entre dos idiomas, el valenciano y el castellano. Esta zona lingüística está suscitando mayor atracción investigativa entre diferentes autores, que a su vez se aproximan a la fisionomía lingüística de esta variedad. Es el caso de Briz (2004), Casanova (1996), Blas Arroyo (1993, 1999), Gómez Molina (2013) o Roselló y Giménez (2017), entre otros $^{2}$. En estos trabajos observamos cómo aparecen fenómenos idiomáticos propios en todos los niveles, es decir, un léxico propio y fenómenos gramaticales y fonéticos consecuentes de la influencia del valenciano.

Sin embargo, muchas de estas características resultan desconocidas para los estudiantes extranjeros cuando llegan a Valencia a estudiar español, ya que las variedades que son fruto de un contacto con la otra lengua que se habla en el territorio, suelen escasear en los grandes mosaicos dialectales del español que se han llevado a cabo en la tradición panhispánica. Estas características que señalamos están extendidas entre los hablantes de la zona, incluso en el nivel culto del habla, por lo que no hablamos de un conjunto de rasgos de convergencia que usa un pequeño grupo en determinados registros del habla.

En definitiva, nuestro objetivo es el de observar el grado de conocimiento previo sobre el español de Valencia de un grupo de estudiantes estadounidenses en programas internacionales de Español como Lengua Extranjera de la Universitat de València, para posteriormente analizar si la adquisición de rasgos de esta variedad ha aumentado después de un curso en este input donde se incluyen actividades específicas.

\section{Metodología. Encuestas sobre las variedades del español y el español de Valencia}

Mediante el uso de una encuesta ${ }^{3}$ inicial y otra final en el aula a dos grupos de estudiantes americanos de nivel avanzado, 9 y 8 estudiantes respectivamente, observaremos si las actividades que hemos llevado a cabo sobre el español de Valencia han modificado la conciencia lingüística de los estudiantes sobre esta variedad. Como

\footnotetext{
${ }^{2}$ Para aproximarse a las características lingüísticas de esta variedad véanse estos artículos.

${ }^{3}$ En las encuestas, los estudiantes usarán pseudónimos para ocultar sus identidades y mantener así su privacidad.
} 
observaremos a continuación, estas preguntas están orientadas a conocer el grado de conocimiento de los estudiantes sobre las variedades del español, en una primera fase, y, en concreto, sobre el español de Valencia en la segunda.

Por otro lado, también incluiremos preguntas iniciales para conocer el grado de conocimiento de español de los estudiantes y el contacto que han tenido con este idioma a lo largo de su vida. Estas preguntas resultarán interesantes para establecer la situación idiomática de partida de los encuestados. Hay que tener en cuenta que el grupo es homogéneo en cuanto a nivel de estudios, siendo universitarios, por lo que esta preguntas no se incluirá en la encuesta. Sí incluiremos los contextos sociolingüísticos de “edad", "sexo", "país de nacimiento" y "lengua nativa"”. También incluiremos "nivel de español", puesto que, pese a que estos programas son para estudiantes de nivel avanzado, resulta interesante saber el grado de conciencia del estudiante sobre su nivel idiomático. El formato de las preguntas iniciales se muestra en la Tabla 1.

Tabla 1 - Preguntas iniciales

\begin{tabular}{|c|c|c|c|c|}
\hline Edad & Sexo & País de nacimiento & Lengua nativa & $\begin{array}{c}\text { Nivel de español (A1, A2, } \\
\text { B1, B2, C1, C2) }\end{array}$ \\
\hline & & & & \\
\hline
\end{tabular}

En segundo lugar, introduciremos preguntas para conocer el grado de contacto que han tenido con el español y su dominio de las variedades de este idioma. Según nuestra experiencia como docentes, el estudiante suele desconocer la heterogénea situación del español en cuanto a sus variedades y suele estar muy influido por el contexto donde lo han estudiado; por su variedad de origen, si son latinoamericanos; o, incluso, la variedad del profesor de español que tuvieron (Tabla 2).

\footnotetext{
${ }^{4}$ Pese a que todos tienen la nacionalidad norteamericana y son angloparlantes, son frecuentes los estudiantes que también tienen el español como lengua nativa o lengua de herencia debido a que tienen un origen latinoamericano.
} 
Tabla 2 - Preguntas sobre las variedades del español

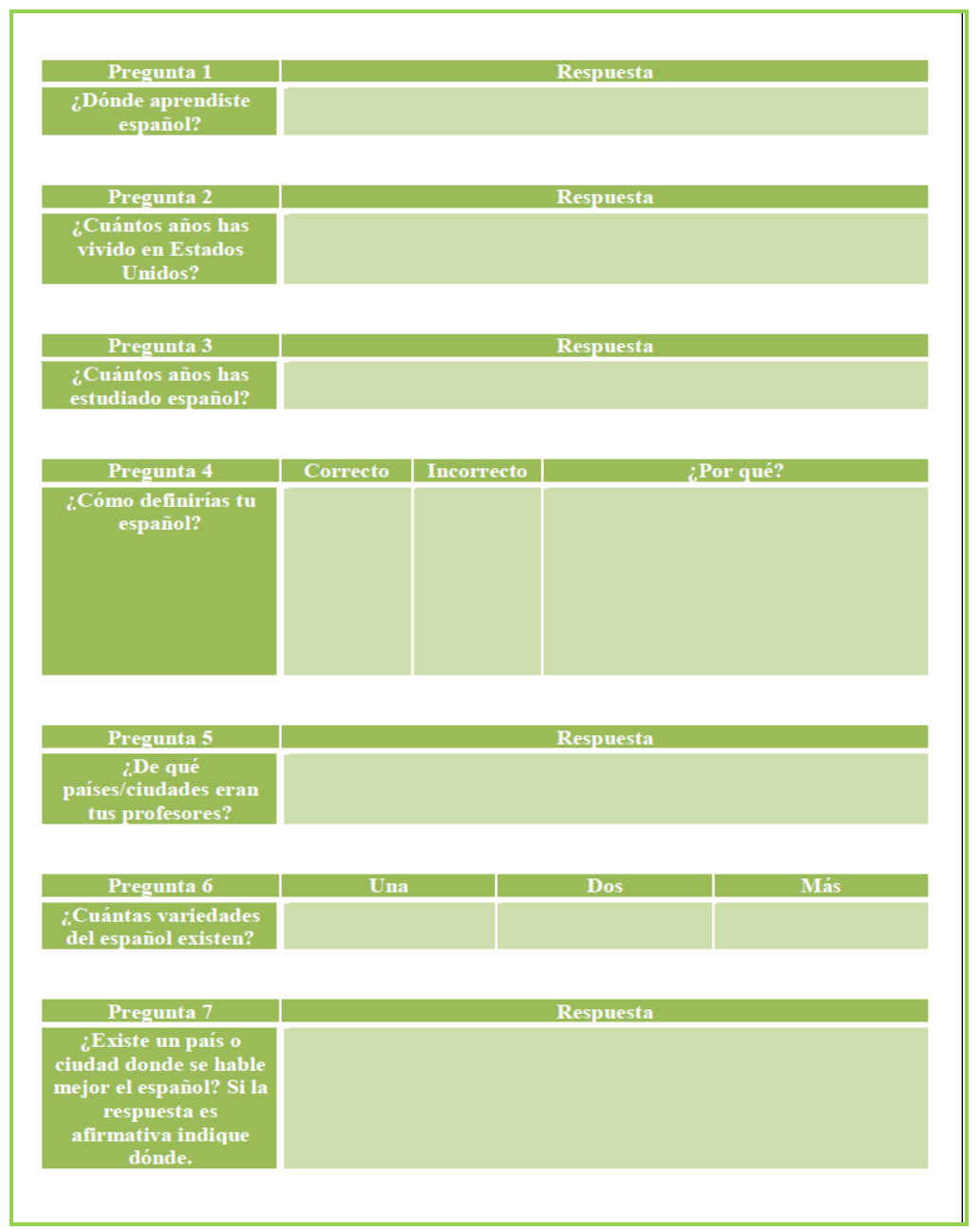

Finalmente, las preguntas serán más específicas sobre la variedad que nos interesa y el conocimiento de los estudiantes sobre ella. En esta última parte, el desconocimiento, salvo en alguna excepción, suele ser casi completo. Quizás hayan escuchado alguna palabra propia del español de Valencia, pero es muy difícil que sepan que esta variedad tiene características propias en todos los niveles lingüísticos debido, entre otros factores, a su contacto con el valenciano (Tabla 3). 
Tabla 3 - Preguntas sobre el español de Valencia

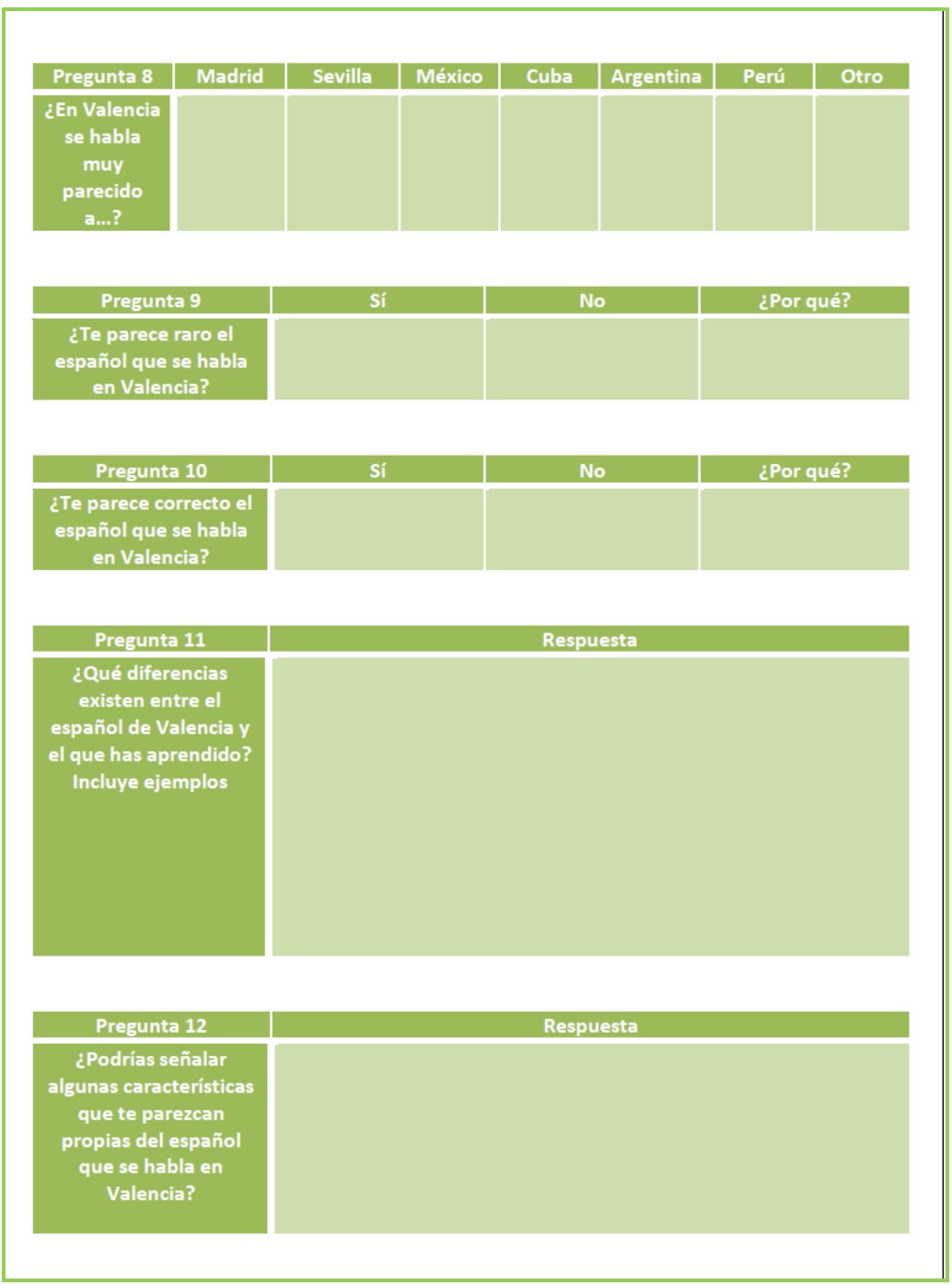

Debido a una situación esperable donde el estudiante suele desconocer la riqueza lingüística de la lengua española y en concreto sobre el input donde va a estudiar español durante este programa, será necesario introducir en clase actividades que cumplan con este cometido y aumenten su conciencia y conocimiento sobre esta situación lingüística. Estas actividades no conformarán en sí mismas el objetivo del programa, ya que hablamos de un curso de español avanzado donde trabajaremos todas las competencias en el aprendizaje de un idioma, pero sí aparecerán integradas entre estas competencias.

Al finalizar el curso, volveremos a pasar entre los estudiantes la misma encuesta para observar si han progresado en cuanto al objetivo que nos interesa y, por lo tanto, si la introducción de estas actividades ha cumplido su función. 


\section{Actividades}

El nivel de español de los dos grupos seleccionados es avanzado, lo cual nos ha permitido utilizar actividades específicas que comportan cierta dificultad ${ }^{5}$. Como hemos explicado en la metodología, estas actividades se integran en el programa del curso, por lo que, a continuación, incluiremos como ejemplo actividades que contemplan el trabajo de diferentes competencias lingüísticas, es decir, comprensión lectora, comprensión auditiva, expresión escrita, expresión oral y la competencia gramatical.

\section{Actividad 1}

En la primera actividad realizaremos un trabajo de comprensión lectora en un contexto que nos permita obtener fenómenos propios del español de Valencia, como es el caso de la festividad de "Las Fallas". En este texto podremos trabajar con palabras propias de esta variedad como "Falla", "fallero", "mascletá" o "ninot". A partir de este texto, podemos mostrar a nuestros estudiantes que palabras como "ninot", "falla" o "fallero" aparecen recogidas en el $D L E$, lo que supone un reconocimiento oficial y académico de esta variedad.

Tabla 4 - Texto sobre las Fallas

\section{Los gestores retan a las comisiones a programar rutas culturales para conocer las propuestas de las distintas sedes expositivas de la fiesta. Los directores de los centros aseguran que es vital recibir ayudas para restaurar los ninots y carteles para garantizar la conservación}

LOLA SORIANO. Sábado, 25 mayo 2019, 00:08

Unas exposiciones muy vivas y con contenidos adaptados a los espectadores del siglo XXI. Esa es la revolución que quieren impulsar los museos falleros de la Comunitat para captar la atención de los visitantes. pero para eso reclamen más ayudas de las administraciones.

En la actualidad la red de estos museos de la fiesta está integrada por seis entidades. Además del museo de Valencia y el que posee el gremio de artistas en Ciudad Fallera se incluyen los de Gandia; Alzira, Xàtiva y Cullera. Y en Castellón, ya está en pleno rendimiento el museo de Burriana que también aspira a integrarse en esta red.

Una de las entidades que en breve se va a actualizar es el museo del gremio. Van a iniciar unas obras para lograr un mayor aprovechamiento del espacio y crear una sala de exposiciones temporales. «La marca Unesco que han logrado las Fallas nos ha permitido optar a unas subvenciones y vamos a

${ }^{5}$ Estas actividades también se pueden utilizar en niveles inferiores realizando una adaptación adecuada al nivel que hayamos elegido. 
aprovechar para hacer mejoras», explica Pilar Luna, responsable del museo del gremio.

\section{El recinto de Cullera contará con 78.000 euros para introducir tecnologías}

En el museo de Cullera, como explica el director Quique Gandia, la idea es «renovar el contenido del museo con nuevas tecnologías para impulsar iniciativas interactivas y sensoriales como usar imágenes en 3D o hacer vibrar al público con la simulación del sonido de una mascletà e incorporaremos pantallas táctiles». El proyecto costará 78.000 euros. La Diputación aportará el 80\% y el resto el Ayuntamiento.

En Alzira, como explica el director Agustí Ferrer, hicieron una mejora de la sede el pasado marzo para remodelar la estructura y museizarlo. Cuentan con paneles que explican el proceso constructivo de los artistas y exponen indumentaria, como un traje de 1945 y otro modelo con el espolín 'Alzira' de 2008.

Uno de los centros más completos es el de Gandia y como indica el director Alberto Bou, «está enfocado a la historia de las fallas; se reproduce una mascletà de forma virtual; se enseñan los pasos de construcción de los ninots; la evolución de los materiales y hay un vídeo que explica el ambiente de un casal». Añade que «hay una parte dedicada a la música de banda y de tabal i dolçaina». El reto ahora es hacer la sede totalmente inclusiva. Ya está adaptado para personas con movilidad reducida y quieren poner lectura Braille en los carteles.

En el museo fallero de Valencia, como expone el director, Gil Manuel Hernández, «el 40\% de los visitantes son extranjeros. Somos museos únicos, que no se pueden ver en otros países, y valoran mucho la experiencia». Como indica, el reto que lanzan a las comisiones de Valencia y de la provincia es que «cuando programen excursiones, apuesten por hacer una ruta por los distintos museos falleros porque en cada uno se puede ver el trabajo de artistas distintos. Es decir, nos gustaría que los falleros hicieran turismo fallero por toda la red de museos como una parte más del aprendizaje».

En el museo de Valencia, por ejemplo, están implantando visitas especializadas como la que se recoge con el nombre de 'museos por la salud. Recuerdos de la fiesta al museo fallero de Valencia', que tiene como finalidad estimular la memoria a largo plazo de los pacientes con Alzheimer.

En el caso de Burriana uno de los atractivos, como explica el director Salvador Doménech, es que muestra una mascletà en 3D de Reyes Martí grabada en Alicante. Además de ninots de falla, incluye muestra de otras tradiciones locales como los tapices florales, las carrozas de 'paperets' y las cruces de mayo.

Entre las reivindicaciones de estos museos, Jesús González, de Xàtiva, indica que «sería importante tener ayudas para restaurar ninots y contar con expertos para garantizar el futuro de estas piezas».

\section{Actividad 2}

En la segunda actividad, además de la comprensión lectora, trabajaremos la expresión oral. En primer lugar, mediante menús de restaurantes valencianos, se le pedirá al estudiante que detecte aquellos platos que desconoce; a continuación, entrará en interacción con otro compañero simulando un role playing donde uno será un 
camarero y el otro un comensal en un restaurante valenciano, para ello usará uno de los menús que aparecen en la actividad. Mediante este ejercicio el estudiante se encontrará con léxico propio de la temática gastronómica del español de Valencia como "paella", "fideuà", "clotxina" u "horchata", entre otras.

Imagen 1 - Menú $1^{6}$ y $2^{7}$.

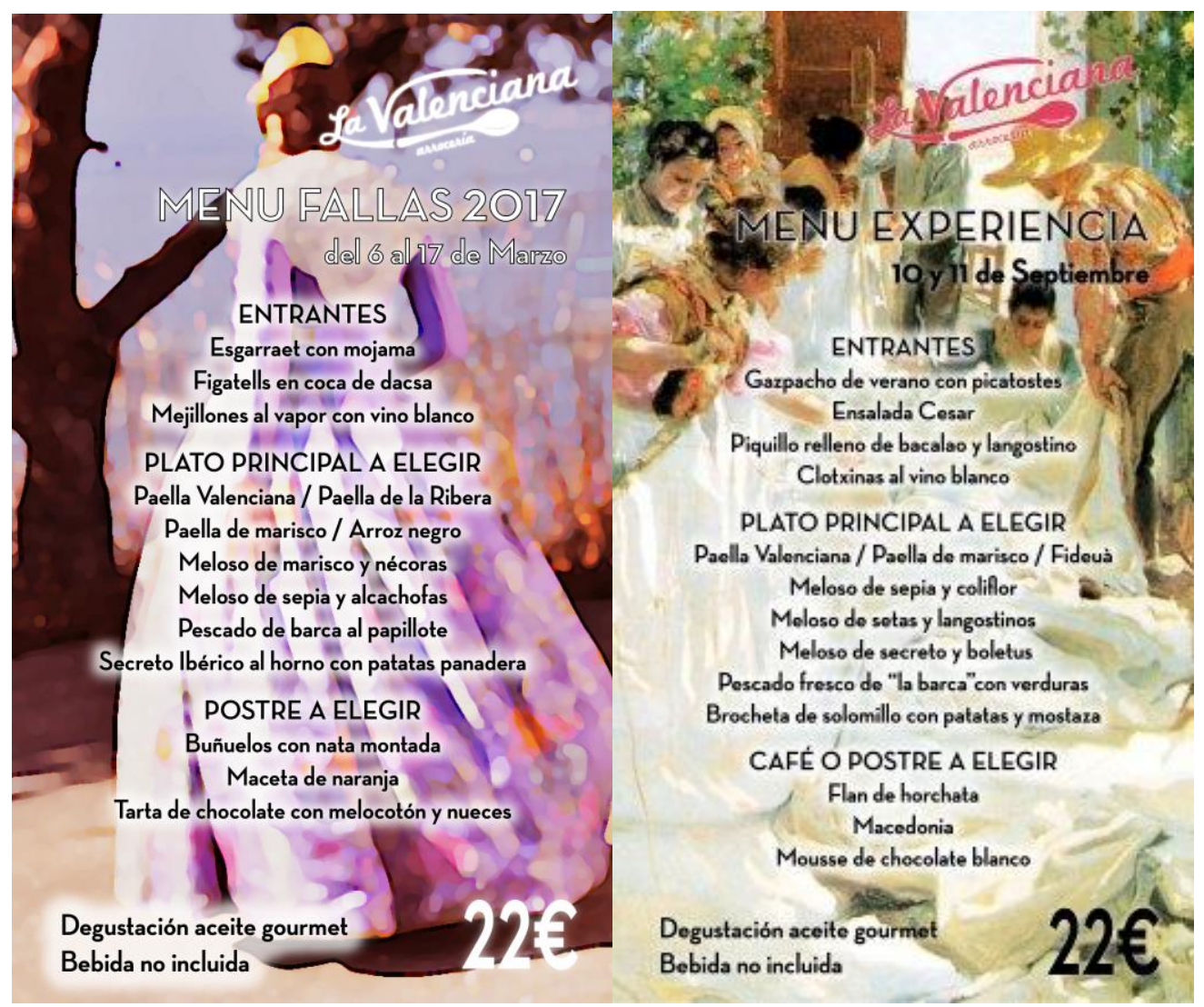

6 Imagen extraída de: https://www.tripadvisor.es/LocationPhotoDirectLink-g187529-d6372967i216495111-Arroceria_La_Valenciana-Valencia_Province_of_Valencia_Valencian_Country.html ${ }^{7}$ Imagen extraída de: https://arrocerialavalenciana.com/menu-fallas-2017-la-valenciana/fallas-22e_web/. 
Imagen 2 - Menús $3^{8}$.

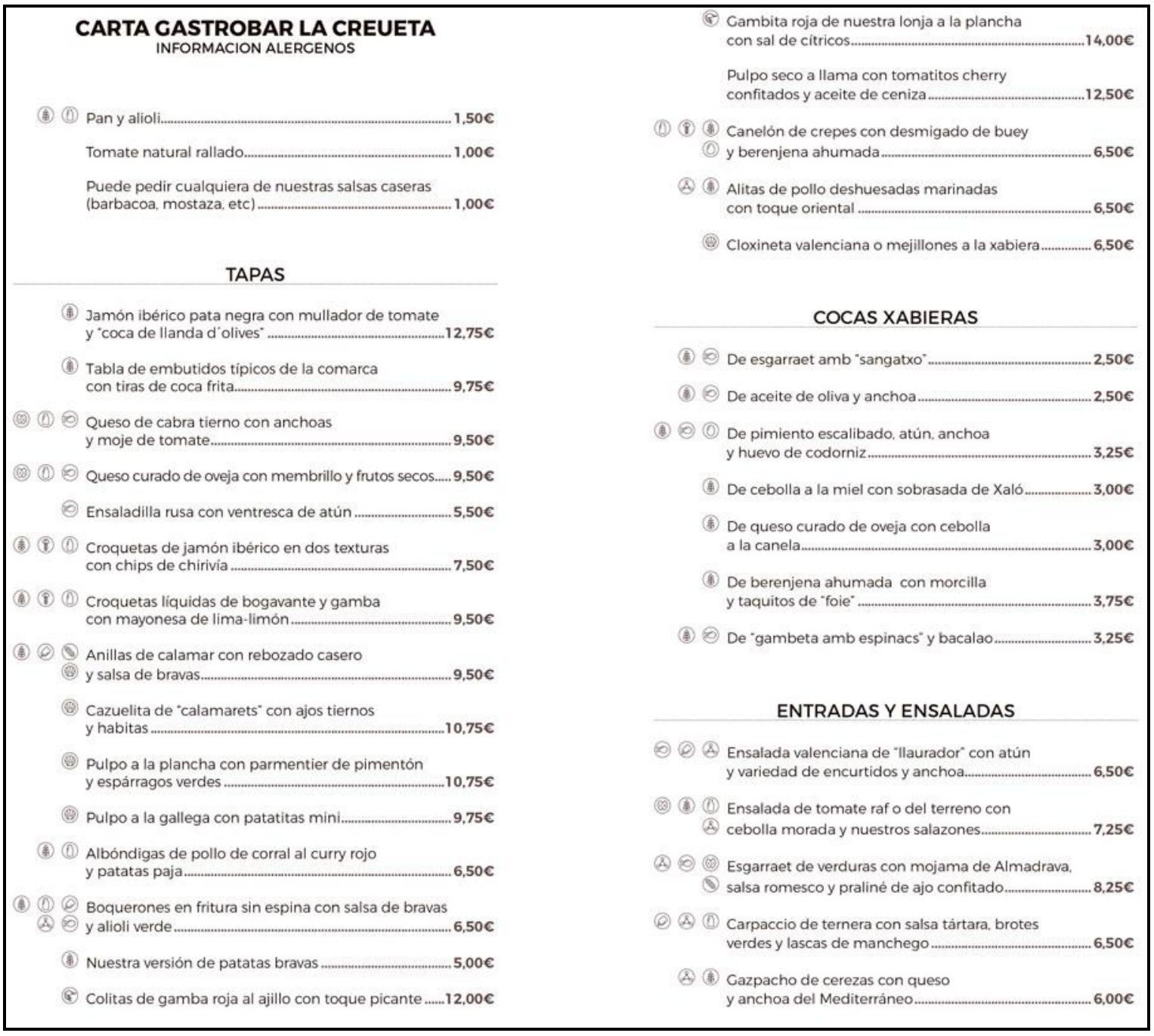

\section{Actividad 3}

En esta última actividad que incluimos como muestra, trabajaremos la comprensión auditiva. Mediante esta audición podremos trabajar con nuestros estudiantes fenómenos que vayan más allá del léxico, como los gramaticales o los fonéticos. Entre los fenómenos gramaticales encontramos ejemplos de pluralización del verbo "haber", la preferencia por el futuro perifrástico o analítico, el leísmo o la inmovilización del pronombre "le" con referentes plurales. En el nivel fonético observamos fenómenos como la pérdida de la "d" intervocálica, el ensordecimiento de la consonante sonora /d/ en posición final o la pronunciación labiodental de la " $\mathrm{v}$ ":

${ }^{8}$ Imagen extraída de: https://www.gastrobarlacreueta.com/wp-content/uploads/2019/04/carta-la-creuetaabril2019-1.jpg

${ }^{9}$ Para obtener información más precisa sobre estos fenómenos véase Roselló y Giménez (2017). 
$\underline{\text { Audición } 1^{10}}$ (entrevista 50).

\section{Resultado de las encuestas iniciales}

En primer lugar, mediante las preguntas iniciales podemos observar, como vemos en la tabla 5, que contamos con un corpus bastante homogéneo, ya que entre los dos grupos contamos con 17 estudiantes con una edad de entre 18 y 21 años, salvo el caso de un estudiante que tiene 27, hay equilibrio en el sexo, el país de nacimiento es Estados Unidos, solo un estudiante señala que comparte el español con el inglés como lengua nativa y 13 de ellos señalan tener un nivel de español C1.

Tabla 5 - Preguntas iniciales contestadas

\begin{tabular}{|l|l|}
\hline Edad & $\begin{array}{l}\text { Entre 18-21 años: 16 } \\
27 \text { años: } 1\end{array}$ \\
\hline Sexo & $\begin{array}{l}\text { Mujeres: } 9 \\
\text { Hombres: } 8\end{array}$ \\
\hline $\begin{array}{l}\text { País } \\
\text { nacimiento de }\end{array}$ & Estados Unidos: 17 \\
\hline Lengua nativa & $\begin{array}{l}\text { Inglés: } 16 \\
\text { Inglés y español: } 1\end{array}$ \\
\hline Nivel de español & $\begin{array}{l}\text { C1: } 13 \\
\text { B2: } 4\end{array}$ \\
\hline
\end{tabular}

Como es lógico, la mayoría de los estudiantes aprendieron español en el ámbito educativo, aunque 2 de ellos lo empezaron a aprender principalmente en casa y otros 2 alternaban su aprendizaje tanto en casa como en los centros educativos. Esto se debe a que el origen de estos 4 últimos estudiantes es latinoamericano y, además, sus padres tienen el español como lengua nativa. Pese a esta pequeña alternancia, todos han vivido en Estados Unidos durante toda su vida. Asimismo, la mayoría ha estudiado español entre 5 y 10 años y sus profesores, generalmente, eran latinoamericanos.

Tabla 6 - Preguntas sobre el contexto de aprendizaje de español

\begin{tabular}{|l|l|}
\hline 1. ¿Dónde aprendiste español? & Colegio, instituto, universidad: 13 \\
& Casa: 2 \\
& Escuela y casa: 2 \\
\hline 2. ¿Cuántos años has vivido en Estados Unidos? & Toda su vida: 17 \\
\hline 3. ¿Cuántos años has estudiado español? & $3-5$ años: 4 \\
& $5-10$ años: 11 \\
& $+10: 2$ \\
\hline 4. ¿Cómo definirías tu español? & Correcto: 15 \\
& Incorrecto: 2 \\
\hline 5. ¿De qué países/ciudades eran tus profesores? & Latinoamérica 11 : 14 \\
& Estados Unidos: 1 \\
& España: 2 \\
\hline
\end{tabular}

${ }^{10}$ Audio extraído del corpus PRESEVAL: https://www.uv.es/preseval/ppal.htm

${ }^{11}$ Los países representados son: Perú, México, Argentina, Puerto Rico, Cuba, Uruguay, Venezuela y Colombia. 
En la última tabla resulta muy interesante observar que 16 de los 17 estudiantes reconocen que hay más de dos variedades del español, con lo cual, son capaces de reconocer la heterogeneidad de este idioma. Este dato resulta lógico, ya que en Estados Unidos han tenido profesores de diferentes procedencias latinoamericanas y ahora, además, se encuentran con una nueva variedad en el español de Valencia. Sin embargo, 8 estudiantes consideran que hay una variedad superior al resto, es decir, México, España en dos ocasiones, Madrid, Perú y Colombia en dos ocasiones, que suele coincidir con la variedad de procedencia de su profesor o de sus padres. El motivo que indican es que les resulta más sencilla de entender esta variedad sobre el resto.

Por otro lado, ya son capaces de marcar diferencias globales con respecto a la variedad que han estudiado, como, por ejemplo, la diferencia entre "vosotros" y "ustedes" o la preferencia por el pretérito perfecto en lugar del pretérito indefinido. Sin embargo, como era esperable, todavía desconocen que en Valencia exista una variedad del español con características específicas propias más allá de las diferencias globales que han señalado y que ocupan grandes zonas dialectales.

Tabla 7 - Preguntas sobre las variedades del español al inicio del curso.

\begin{tabular}{|c|c|}
\hline 6. ¿Cuántas variedades de español existen? & $\begin{array}{l}\text { Una: } 0 \\
\text { Dos: } 1 \\
\text { Más: } 16\end{array}$ \\
\hline $\begin{array}{l}\text { 7. ¿Existe un país o ciudad donde se hable } \\
\text { mejor el español? }\end{array}$ & $\begin{array}{l}\text { Sí: } 8 \\
\text { No: } 9\end{array}$ \\
\hline 8. ¿En Valencia se habla muy parecido a....? ${ }^{12}$ & $\begin{array}{l}\text { Madrid: } 10 \\
\text { Sevilla: } 5 \\
\text { México: } 1 \\
\text { Cuba: 0 } \\
\text { Argentina: } 0 \\
\text { Perú: 0 } \\
\text { Otro: } 3^{13}\end{array}$ \\
\hline $\begin{array}{l}\text { 9. ¿Te parece raro el español que se habla en } \\
\text { Valencia? }\end{array}$ & $\begin{array}{l}\text { Sí: } 5 \\
\text { No: } 12\end{array}$ \\
\hline $\begin{array}{l}\text { 10. ¿Te parece correcto el español que se habla } \\
\text { en Valencia? }\end{array}$ & $\begin{array}{l}\text { Sí: } 15 \\
\text { No: } 2\end{array}$ \\
\hline $\begin{array}{l}\text { 11. ¿Qué diferencias existen entre el español de } \\
\text { Valencia y el que has aprendido? }\end{array}$ & $\begin{array}{l}\text { Marca diferencias: } 15 \\
\text { No marca diferencias: } 2\end{array}$ \\
\hline $\begin{array}{l}\text { 12. ¿Podrías señalar algunas características que } \\
\text { te parezcan propias del español que se habla en } \\
\text { Valencia? }\end{array}$ & $\begin{array}{l}\text { Marca características propias: } 1 \\
\text { No marca características propias: } 16\end{array}$ \\
\hline
\end{tabular}

${ }^{12}$ En esta pregunta se puede marcar más de una respuesta.

${ }^{13}$ Barcelona o ninguna son las ciudades marcadas como "otro". 


\section{Resultado de las encuestas finales}

A final de curso, una vez realizado el programa donde se integraban actividades como las presentadas en este trabajo, volvimos a pasar las mismas encuestas a los estudiantes de ambos grupos para comprobar si se habían producido modificaciones. Únicamente tuvieron que completar a partir de la pregunta 6, ya que, como hemos señalado anteriormente, las 5 primeras cuestiones tienen que ver con el contexto idiomático del estudiante que continúa siendo el mismo.

Como podemos observar en la tabla, los resultados resultan satisfactorios en cuanto a la influencia de las actividades realizadas en clase y, de este modo, el conocimiento de los estudiantes sobre la variedad del español de Valencia. El resultado más evidente tiene que ver con la última pregunta donde 16 de los 17 estudiantes marcan características propias del español de Valencia. En estas respuestas los 16 indican ejemplos léxicos: "falla, ninot, esgarraet, clóchina, paella, butifarra, horchata, mascletá, fideuá, nano, che, palometa (percha), choparse, chepa, mocho, camal, yayo, faena, paraeta, fava (tonto/a) ${ }^{14}$ ". Asimismo, 8 estudiantes indican características de otros niveles lingüísticos; 7 de estos 8 estudiantes señalan fenómenos fonéticos, en concreto el ensordecimiento de la consonante sonora /d/ en posición final, la pérdida de la /d/ intervocálica en participios ${ }^{15}$ y la mayor abertura de las vocales /e/ y /o/. Finalmente, de estos 8 estudiantes, 2 señalan, además, el ejemplo de la pluralización del verbo "haber".

Por otro lado, en cuanto a esta variedad del español de Valencia los resultados en las otras preguntas también son más exactos. Por ejemplo, en la pregunta 8 , donde ya nadie marca Sevilla como ciudad que tiene una variedad parecida a la que se habla en Valencia ${ }^{16}$; en la pregunta 9 solo a 1 estudiante le parece extraño el español que se habla en Valencia; y en la 10, donde todos reconocen al español que se habla en Valencia como correcto.

Finalmente, resulta curioso observar que además del mayor conocimiento sobre la variedad del español de Valencia, también adquieren una mayor concienciación sobre la heterogeneidad del español. Este dato lo podemos observar en la pregunta 6, donde el único estudiante que no había marcado la tercera opción "más de dos variedades" ahora

${ }^{14}$ Para ver el significado de estas voces puede consultarte Giménez (2017).

${ }^{15}$ Aunque este fenómeno no sea específico del español de Valencia, sí aparece con frecuencia.

${ }^{16}$ Hay que señalar que la mayoría de estudiantes viajó a Andalucía durante el curso, hecho que permitió que conocieran mejor sus variedades. 
sí lo ha hecho y en la pregunta 7, donde 5 estudiantes más, con respecto a la encuesta inicial, piensan que no existe una variedad mejor que otra.

Tabla 8 - Preguntas sobre las variedades del español al final del curso.

\begin{tabular}{|l|l|}
\hline 6. ¿Cuántas variedades de español existen? & Una: 0 \\
& Dos: 0 \\
& Más: 17 \\
\hline $\begin{array}{l}\text { 7. ¿Existe un país o ciudad donde se hable } \\
\text { mejor el español? }\end{array}$ & Sí: 3 \\
\hline 8. ¿En Valencia se habla muy parecido a....? & Ma: 14 \\
& Sevilla: 0 \\
& México: 0 \\
& Cuba: 0 \\
& Argentina: 0 \\
\hline 9. ¿Te parece raro el español que se habla en & Perú: 0 \\
Oalencia? & Sí: 1 \\
\hline 10. ¿Te parece correcto el español que se habla \\
en Valencia? & No: 16 \\
\hline 11. ¿Qué diferencias existen entre el español de 17 \\
Valencia y el que has aprendido? & No: 0 \\
\hline 12. ¿Podrías señalar algunas características que diferencias: 16 \\
te parezcan propias del español que se habla en & No marca diferencias: 1 \\
Valencia? & No marca características propias: 1 \\
\hline
\end{tabular}

\section{Conclusiones}

Mediante este trabajo, ha quedado demostrado que la introducción de actividades orientadas al trabajo de las variedades del español tienen un efecto positivo en el aprendizaje del estudiante de E/LE. Esta orientación se presenta como necesaria en un idioma tan heterogéneo como el español donde las variedades son múltiples, por lo que un aprendizaje donde el estudiante conozca únicamente una variedad resultará, por lo tanto, incompleto.

En el campo de estudio aquí presentado, trabajamos con una variedad con características propias como es el español de Valencia, donde los estudiantes llegan con un bagaje idiomático determinado, en el que predomina el conocimiento de una única variedad. Consecuentemente, la primera tarea que realizamos en el aula es la de mostrar a nuestros estudiantes la existencia de más variedades como, por ejemplo, la que van a descubrir en esta ciudad. Este trabajo se realiza con actividades como las incluidas en esta propuesta donde se trabajan todos los niveles lingüísticos del idioma $\mathrm{y}$, a su vez, diferentes competencias de aprendizaje.

\footnotetext{
17 Barcelona en ambos casos.
} 
Finalmente, mediante las encuestas al inicio y al final del curso hemos comprobado la validez de estas actividades en dos sentidos: la mayor concienciación sobre las variedades del español, por un lado, y el conocimiento de características propias de la variedad del español de Valencia, por el otro. Resulta satisfactorio, por lo tanto, observar que los estudiantes han conseguido retener características fonéticas, gramaticales y léxicas que, en definitiva, escucharán cuando salgan del aula entre los hablantes nativos de Valencia.

En conclusión, propuestas como esta colaborarán a que los estudiantes obtengan una amplia sensibilidad hacia otras variedades del español evitando, de esta manera, afirmaciones en las que se indique la existencia de una variedad mejor que otra y, por lo tanto, la existencia de variedades con menor prestigio. De este modo, el estudiante se adaptará más fácilmente cuando se encuentre con otras variedades del español.

\section{REFERENCIAS}

BLAS ARROYO, José Luis. La interferencia lingüística en Valencia (dirección catalán-castellano): Estudio sociolinguiístico. Castellón: Universitat Jaume I. 1993.

BLAS ARROYO, José Luis. Lenguas en contacto. Consecuencias del bilingüismo social en las comunidades de habla del este peninsular. Madrid: Vervuert. 1999.

BRIZ GÓMEZ, Antonio. El castellano en la Comunidad Valenciana. Revista internacional de lingüística iberoamericana, p. 119-130. 2004.

CASANOVA, Emilio. El castellà de València. En Pragmática y gramática del español hablado. Actas del II Simposio sobre análisis del discurso oral. Zaragoza: Pórtico, p. 293-298. 1996.

GIMÉNEZ FOLQUÉS, David. ¿Es conveniente enseñar las variantes del español en clase de E/LE?. Ricognizioni. Rivista di Lingue e Letterature straniere e Culture moderne, Italia, p. 31-37. 2015.

GIMÉNEZ FOLQUÉS, David. 100 voces y expresiones del español de Valencia en el aula de ELE. Revista Foro de profesores de E/LE, Valencia, p. 131-141. 2017.

\section{GÓMEZ MOLINA, José Ramón (coord.). El español de Valencia. Estudio} sociolinguiístico. Berna: Peter Lang. 2013.

MORENO FERNÁNDEZ, Francisco. La enseñanza del español como lengua extranjera. En Marqués de Tamarón (coord.). El peso de la lengua española en el mundo. Valladolid: Universidad de Valladolid, p. 195-233. 1995. 
REAL ACADEMIA ESPAÑOL Y ASOCIACIÓN DE ACADEMIAS DE LA LENGUA ESPAÑOLA. Diccionario de la lengua española (23. ed.). Editorial Espasa. 2014.

ROSELLÓ VERDEGUER, Jorge y GIMÉNEZ FOLQUÉS, David. El español hablado en Valencia. Interferencia lingüística y enseñanza de la lengua. Revista Foro de profesores de E/LE, Valencia, p. 143-153. 2017.

\section{Cómo citar este artículo}

GIMÉNEZ FOLQUÉS, David. El español de Valencia en clase de E/LE. Una experiencia con alumnos estadounidenses. Rev. EntreLínguas, Araraquara, v. 5, n. esp. 1, p. 266-281, jul., 2019. E-ISSN: 2447-3529. DOI: 10.29051/el.v5iesp.1.12985

Submetido em: 01/06/2019

Aprovado em: 30/06/2019

Publicado em: 01/10/2019 